Faculdade de Ciências Econômicas UFRGS
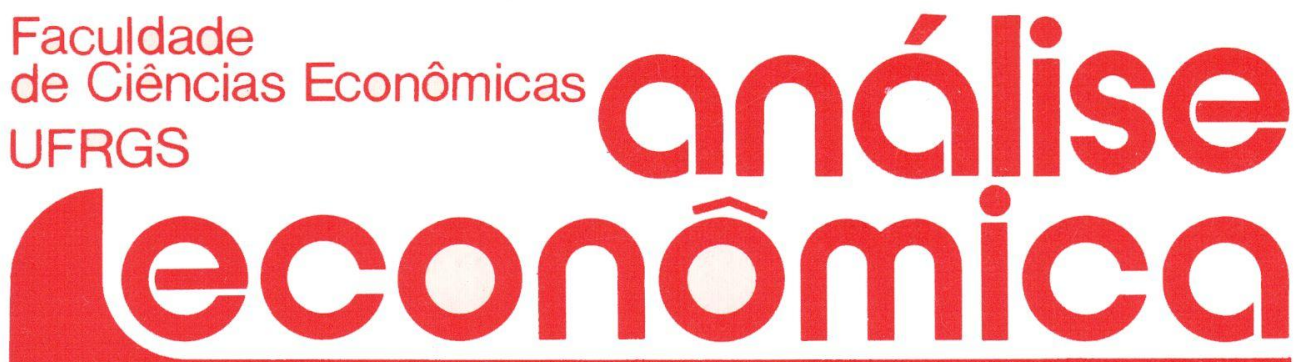

nesta edição:

- PRODUÇÃO DE ÁLCOOL E EMPREGO Otto G. Konzen e Juvir L. Mattuella

- NECESSIDADE DE PENSAR E CONSTRUIR O PÓS-CRISE Marcus Vinicius Pratini de Moraes

- CONTAS EXTERNAS

Fernando Ferrari Filho

- FETICHISMO

Leda Maria Paulani

- CRISE DO CAPITALISMO MUNDIAL Beki Morón de Macadar

- EXPANSÃO CAFEEIRA NO ESPÍRITO SANTO José L. Celin
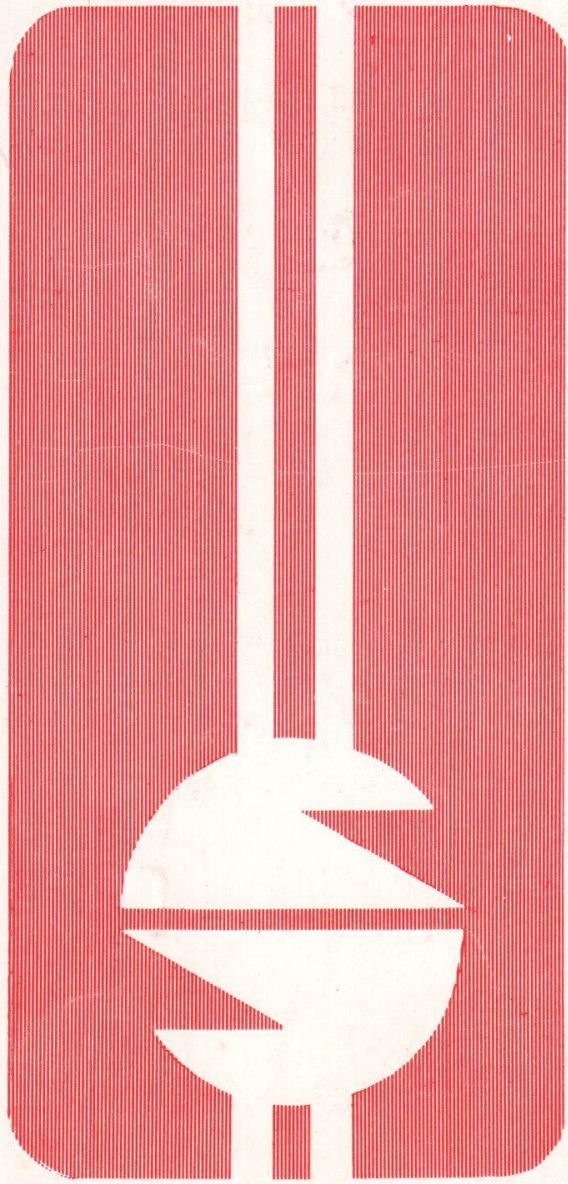
DIRETOR DA FACULDADE DE CIÉNCIAS ECONOMMICAS:

Prof. Antonio Carlos Santos Rosa/Prof. Edgar Irio Simm

VICE-DIRETOR:Prof. Nelson Rokembach/Prof. Walter Meucci Nique

CHEFE DO DEPARTAMENTO DE CIẼNCIAS ECONÔMICAS:

Prof. Renato Batista Masina

CONSElHo EdITORIAL: Prof. Pedro Cezar Dutra Fonseca (Presidente)

Prof. Achyles Barcelos da Costa

Prof. Carlos Augusto Crusius

Prof. Claudio Francisco Accurso

Prof. Edgar Augusto Lanzer

Prof. Ernani Hickmann

Prof. Nali de Jesus de Souza

Prof. Nuno Renan Lu de Figueiredo Pinto

Profa Otilia Beatriz Kroeff Carrion

Prof. Roberto Camps Moraes

Profạ Yeda Rorato Crusius

FUNDADOR: Prof. Antonio Carlos Santos Rosa

ANALISE ECONÔMICA publica dois números anuais, nos meses de março e novembro. O preço da așsinatura para 1985 é $\mathrm{Cr} \$ 6.000,00$, a ser pago através de cheque nominal para "Faculdade de Ciências Econômicas - UFRGS". Aceita-se permuta com revistas congêneres. Aceitam-se, também, livros para elaboração de resenhas ou recensões.

Toda a correspondência, material para publicação, assinaturas e permutas devem ser dirigidas a:

Prof. PEDRO CEZAR DUTRA FONSECA

Revista Análise Econômica

Avenida João Pessoa, $52-3 \%$ andar

90.000 - Porto Alegre (RS) - Brasil 


\title{
FETICHISMO: teoria geral das relações de produção na economia mercantil-capitalista*
}

\author{
LEDA MARIA PAULANI**
}

R. Rosdolsky coloca, no capítulo 9 de seu Génesis y Estructura de El Capital de Marx uma pergunta extremamente pertinente sobre a lógica das idéias desenvolvidas por Marx em O Capital. A resposta a essa questão envolve uma compreensão muito clara do método utilizado por Marx na elaboração de sua obra e parece revelar a importância vital assumida pelo fetichismo na busca das relações mais gerais que dominam a economia mercantil-capitalista.

Eis a questão: "(..) Assim, evidentemente, a categoria do capital não pode desenvolver-se sem a da mercadoria, a do valor e a do dinheiro; mas parece igualmente certo que estas categorias sumamente gerais só podem formar-se do todo baseando-se no capital e em seu modo de produção. Como pode desenvolver-se esta 'contradição', e qual das duas interpretações da seqüência evolutiva é a correta?"1

Assim, em última instância o que se questiona é a validade da lei do valor, ou até que ponto pode se explicar a economia capitalista plenamente desenvolvida por intermédio das categorias e relações mais gerais e mais abstratas aparentemente "deduzidas" de

\footnotetext{
* A autora agradece ao Prof. Eleutério F.S. Prado as valiosas contribuições oferecidas sobre o tema. Exime-o, contudo, das falhas ou equivocos porventura existentes neste paper * Em doutoramento no Instituto de Pesquisas Econômicas da Universidade de São Paulo. 1 - Rosdolsky, R. - Génesis y Estructura de El Capital de Marx, Sigio XXI Editores, p. 203 .
}

ANÁLISE ECONOMICA ANO 2 No 4 NOV $/ 1984$ p $41 \cdot 6$ 
uma economia mercantil simples. A resolução desse "impasse" insere-se, como já se adiantou, na esfera metodológica da questão.

Apesar de insistentes leituras em contrário (vide Althusser ${ }^{2}$ ), parece inegável que Marx carrega para as páginas de $O$ Capita/ uma herança hegeliana considerável. Tal como Hegel, Marx busca na realidade o universal, ainda que esse universal seja, para ele, pressuposto objetivo do pensamento e não o resultado desse mesmo pensamento. Nesse sentido, as próprias palavras de Marx esclarecem mais do que possa fazê-lo qualquer comentário. Em Para a Crítica da Economia Política ele coloca frontalmente sua posição a esse respeito:

“(...) O último método é manifestamente o método científico exato. O concreto é concreto porque é a síntese de muitas determinações, isto é, unidade do diverso. Por isso o concreto aparece no pensamento como processo da síntese, como resultado, não como ponto de partida, ainda que seja o ponto de partida efetivo e, portanto, o ponto de partida também da intuição e da representação. No primeiro método a representação plena volatiliza-se em determinações abstratas, no segundo as determinações abstratas conduzem à reprodução do concreto por meio do pensamento. Por isso é que Hegel caiu na ilusão de conceber o real como resultado do pensamento que se sintetiza em si, se aprofunda em si, e se move por si mesmo; enquanto que o método que consiste em elevar-se do abstrato ao concreto não é senão a maneira de proceder do pensamento para se apropriar do concreto, para reproduzi-lo como concreto pensado. Mas esse não é de modo nenhum o processo da gênese do próprio concreto." 3

Parece cristalino, portanto, que o método de Marx é um método lógico-ontológico de busca e apreensão das determinações

2 - Em Para Leer El Capital, siglo XXI Editores, diz Althusser: "Se temos podido estabelecer, com provas suficientes para afirmar, que o discurso de Marx é, em seus princípios, estranho ao discurso de Hegel, que sua dialética (...) é totalmente diferente da dialética hegeliana, não passamos disso. Não chegamos a descobrir de onde obteve Marx este método de análise que ele considera preexistente. Não nos colocamos a questão de saber se Marx, em lugar de tomá-lo emprestado, não teria inventado este método que ele acreditava somente estar aplicando, da mesma forma como teria certamente inventado essa dialética que (...) declara ter tomado de Hegel. E se essa análise e essa dialética não são, como cremos, senão uma única e mesma coisa, não basta, para explicar sua produção original, assinalar que ela só foi possivel ao preço de uma ruptura com Hegel." p. 57. grifos do Autor.

3 - Marx, K - Para a Crítica da Economia Política - Coleção "Os Pensadores" - Abril Cultural, p. 122, grifos do Autor. 
mais gerais e mais abstratas da economia capitalista, as quais jamais podem existir e ter pleno desenvolvimento senão dentro de um todo vivo, concreto e multiplamente determinado, ainda que, no processo de exposição, tomem a forma de deduções de um concreto mais simples e anterior.

É desse modo, portanto, que o valor só tem sentido enquanto valor que se valoriza, ou seja, dentro do circuito D-M-D', de modo que a lei do valor não existe em estado puro; que a mercadoria só assume a condição de categoria dominante na economia quando o próprio trabalho transforma-se em mercadoria, etc.

Assim, não existem em $O$ Capital duas concepções diferentes, uma para a economia mercantil simples e outra para a capitalista, nem tampouco desenvolveu Marx suas idéias sobre a última tomando por base as leis que havia deduzido para a primeira. O que existe, como afirma Rosdolsky, é um único e mesmo modo de ser, o modo de produção capitalista, cujo método de conhecimento desenvolvido por Marx consistiu em elevar-se do abstrato ao concreto e desvendar, por conseguinte, as leis internas de seu funcionamento.

E em que consiste o fetichismo analisado por Marx? Consiste no fato de que os produtos do trabalho aparecem aos olhos dos homens como dotados de propriedades sociais naturais tão logo assumem a forma de mercadoria. Essas propriedades sociais, obviamente, não pertencem à natureza das coisas enquanto coisas físicas, senão derivam das características sociais do próprio trabalho humano e, em conseqüência, da relação entre cada trabalho individual e o trabalho total na economia capitalista. Assim as relações de produção entre os homens se dão não pelas coisas mas através das coisas como lembra J. J. Rubin em seu A Teoria Marxista do Valor. ${ }^{4}$ Segundo as palavras de Marx no capítulo 1 de O Capital:

"(...) Não é mais nada que determinada relação social entre os próprios homens que para eles aqui assume a forma fantasmagórica de uma relação entre coisas. (...) Isso eu chamo o fetichismo que adere aos produtos do trabalho, tão logo são produzidos como mercadorias, e que, por isso, é inseparável da produção de mercadorias."

4-Rubin, J. J، - A Teoria Marxista do Valor, Ed. Brasiliense.

5 - Marx, K. - O Capital - Volume I - Coleção "Os Economistas" - Abril Cultural, p. 71 
É bem verdade, e o próprio Marx sublinha isso, que na sociedade mercantil-capitalista as coisas (produtos do trabalho) plasmam relações sociais de modo que o fetichismo é, por assim dizer, inerente ao modo de ser do sistema. Partindo da forma simples de valor ( $x$ de $A=y$ de $B$ ) descobre-se que uma determinada mercadoria, tal qual ela é, expressa valor, pois que o valor de $A$ está expresso no valor de uso de B, ou seja, B serve de material para a expressão do valor de $A$. Esse valor assim expresso, entretanto, só é efetivo do ponto de vista interno da relação; no entanto, ele aparece como natural e eterno porque, julgam as pessoas, as propriedades das coisas não se originam de suas relações com outras coisas, são-Ihes natas. Justifica-se, pois, plenamente o fetichismo que adere à forma mercadoria, bem como à sua seqüência valor-dinheiro-capital.

A conseqüência desse processo de "reificação das relações de produção" entre as pessoas é justamente a "personificação das coisas", já que, na sociedade mercantil-capitalista, as pessoas mantêm relações de produção diretas unicamente enquanto proprietárias de coisas. Jl. I. Rubin esclarece:

"A presença de uma coisa com uma determinada forma social nas mãos de uma dada pessoa a induz a manter determinadas relações de produção e Ihe infunde seu caráter social específico. A 'reificação das relações de produção entre as pessoas' é agora complementada pela 'personificação das coisas'."

E o que faz a economia vulgar criticada por Marx? A economia vulgar estuda a forma pronta das coisas, sua aparência. Segundo Rubin, a economia vulgar apreende apenas o que ocorre na superfície da vida econômica e, nesse sentido, não se dá conta do processo de "reificação das relações de produção entre as pessoas", restringindo-se a ver o movimento entre agentes econômicos proprietários de fatores de produção. Dessa forma, sem perceberem que este último processo é o processo de "personificação das coisas", e que, portanto, só tem razão de ser se for entendido como resultado do primeiro processo ("'reificação das relações de produção"), tornam-se esses economistas as primeiras e maiores vítimas do fetichismo, pois passam a considerar a característica social das coisas como características naturais dessas coisas.

6 - Rubin, 1. 1. - op cit., p. 37 
Contudo, isso só acontece porque esses economistas achamse limitados pelo horizonte da economia capitalista, ainda que disso não se apercebam. Ao percorrerem esse caminho, ou seja, ao considerarem as características sociais das coisas como características próprias das coisas, tendem a enxergar a forma capitalista de produção como a forma natural e eterna, pois que é "natural" aos produtos do trabalho possuírem valor. De outra parte, ao entenderem o modo burguês de produção como natural e eterno deixam de perceber o que ele tem de especifico, de historicamente deter. minado, e assim fecha-se o circuito.

Não é à toa, pois, que Marx vai encontrar no capital o universal buscado por Hegel, só que o capital não é o "Espírito Absoluto", porque é historicamente determinado, e além disso o capital realiza o concreto "pelo avesso" pois sempre é aquilo que não parece e nunca parece o que realmente é. Essa fantástica capacidade fetichista do capital tem sua origem na mercadoria, a determinação mais abstrata e, no entanto, também a mais geral do modo capitalista de produção. À medida que se evolui da categoria mercadoria em direção à categoria capital vai ocorrendo um crescente acobertamento das relações sociais subjacentes ao processo, que tornam-se então cada vez mais opacas e invisiveis. ${ }^{7}$

É este o fundamento objetivo do fetiche que leva de imbróglio não só os reles mortais participantes ativos da produção, como também os mais iluminados economistas.

Então, o fetichismo não pode ser tratado como uma entidade separada da teoria econômica de Marx, como um capítulo à parte em sua obra. Contrariamente, ele só tem razão de ser se for entendido como uma teoria geral das relações de produção na economia capitalista. ( $\mathrm{E}$, no entanto, informa Rubin, tanto adversários quanto defensores do marxismo tratam o fetiche como algo pouco relacionado internamente ao corpo teórico da análise de Marx.) Nesse sentido, se fosse possivel elaborar uma graduação, o fetiche do capital seria muito maior que o do dinheiro, que por sua vez seria muito maior que o do valor de troca, etc.

Parece evidente mais uma vez, e fechando a questão, que Marx não "descobriu" o fetiche analisando formas de valor de economias mercantis simples transportando-as posteriormente para a já complexa sociedade capitalista de sua época. Parece mais razoá-

7 - A esse respeito diz Marx sobre o dinheiro no capítulo 1 de O Capital." essa forma acabada - a forma dinheiro do mundo das mercadorias que objetivamente vela, em vez de revelar, o caráter social dos trabalhos privados e, portanto, as relações sociais entre os produtores privados'. p. 73. 
vel crer que Marx dissecou dialeticamente as categorias concretas que a realidade lhe apresentava (e que constituíram seu ponto de partida efetivo) e que, nesse processo, chegou às determinações mais gerais e mais abstratas que lhe permitiram reproduzir o concreto como concreto pensado. Esse concreto pensado por Marx está guarnecido por leis internas de funcionamento que ele dissecou no decorrer do processo, e o fetiche, ao que parece, é a mais geral de todas as leis. E é por ser a mais geral que Marx só conseguiu explicar o capitalismo invertendo o caminho que vinha sendo perseguido historicamente pela ciência econômica que nascia.

\section{BIBLIOGRAFIA}

ALTHUSSER, L. e BALIBAR, E., Para leer El Capital, México, Siglo XXI Editores, 6a ed., 1973.

BELLUZZO, L. G. M., Valor e Capitalismo, São Paulo, Ed. Brasiliense, 1980.

MARX, K., O Capital, Vol. 1, São Paulo, Abril Cultural, "Os Economistas", 1983.

MARX, K., Para a Crítica da Economia Politica, São Paulo, Abril Cultural, “Os Pensadores", 1974.

ROSDOLSKY, R., Génesis y Estructura de "El Capital" de Marx, México, Siglo XXI Editores.

RUBIN, I. I., A Teoria Marxista do Valor, São Paulo, Ed. Brasiliense, 1980. 